\title{
Detection of Herpes Simplex Virus Infection in Cerebrospinal Fluid
}

Nourollah Ramroodi (MD)

Department of Neurology, Zahedan

University of Medical Science,

Zahedan, Iran

Mohammad Taghi Kardi (MSc)

Department of Microbiology, Mahdieh

Laboratory, Isfahan, Iran

Marzieh Rezaei (MSc)

Department of Biology, Faculty of

Science, University of Isfahan, Isfahan, Iran

Majid Bouzari (PhD)

Department of Biology, Faculty of

Science, University of Isfahan, Isfahan, Iran

Majid Komijani (PhD)

Department of Biology, Faculty of

Science, University of Isfahan, Isfahan,

Iran

Mahsa Yazdi (MSc)

Department of Biology, Faculty of

Science, University of Isfahan, Isfahan,

Iran

Corresponding author: Mohammad Taghi Kardi

Email: m.kardi@gmail.com

Tel: +989133094626

Adderess: Department of

Microbiology, Mahdieh Laboratory,

Isfahan, Iran

Received : 28 Jun 2015

Revised: 31 Aug 2015

Accepted: 29 Jan2016

\section{ABSTRACT}

Background and Objective: Herpes simplex encephalitis is a life-threatening consequence of the central nervous system (CNS) infection with Herpes simplex virus (HSV). Although it is a rare disease, mortality rates reach $70 \%$ in the absence of therapy and only a minority of individuals can return to normal function. The aim of this study was to determine possible correlation between HSV infection and the incidence of encephalitis in patients with neurological signs.

Methods: 0verall, 152 CSF samples were tested from patients with neurological signs referred to Mahdieh Clinical Laboratory in Isfahan from 2010 to 2013. After cerebrospinal fluid (CSF) collection, DNA was extracted and real-time polymerase chain reaction (PCR) was performed for HSV detection.

Results: 0f 152 patients tested, 50 were diagnosed with encephalitis. HSV DNA was present in the CSF of 13 patients with encephalitis. HSV was significantly higher $(p<0.05)$ in patients with encephalitis, which shows the significance of infection as an etiological factor of this disease. About $60 \%$ of the encephalitis cases were in age range of 1-24 months.

Conclusion: According to the findings of the present study, Cesarean section is recommended for HSV-positive mothers. A routine real-time PCR test is suggested for HSV detection in patients with encephalitis to avoid unnecessary antiviral treatments.

KEYWORIDS: Encephalitis, Herpes simplex virus, Real-Time PCR. 


\section{INTRODUCTION}

Herpes simplex virus (HSV) is one of the main causes of viral infections of the central nervous system (CNS). HSV1 and HSV2 are the members of the Herpesviridae family, alphaherpesvirus subfamily (1). Following infections of skin and mucocutaneous epithelium, the virus reaches peripheral ganglions and then CNS through axonal route and causes encephalitis or latent infection in the cell bodies of the neurons $(2,3)$. HSV infection can be localized to skin, eye and mouth (SEM disease), involve the CNS or manifest as disseminated infection involving multiple organs $(4,5)$. HSV is the most common cause of acute, sporadic viral encephalitis in the world, especially in the United States $(1,4)$. The rapid diagnosis of CNS infection with this virus is important because of the risk of morbidity and mortality associated with HSV encephalitis (HSVE) and the availability of antiviral therapy with acyclovir that is proven to ameliorate this disease. Without therapy, more than $70 \%$ of HSVE cases are fatal and about $11 \%$ of the surviving patients recover normal function $(6$, 7). Treatment with acyclovir has been shown to reduce the mortality rate to about $20 \%$ for patients of all ages $(7,8)$. The broad spectrum of clinical syndromes associated with HSV infection of the CNS usually presents as neonatal infection, encephalitis, or meningitis. Neonatal HSV infection is often caused by vertical transmission of HSV2 during delivery, usually with dissemination and mortality rate similar to that for HSVE (9). HSVE presents with an acute onset, localized CNS findings, and necrosis of brain parenchyma (classically of the temporal and/or frontal lobes) and may occur in patients of any age beyond the neonatal period. It is the most common cause of sporadic fatal encephalitis in the United States (10) and is predominantly caused by HSV1 (11-13). The traditional methods of laboratory diagnosis of HSV CNS infections are either extremely invasive (14) or insensitive (12) or lack clinical significance (14). Rowley et al. in 1990 reported the first polymerase chain reaction (PCR)-based detection of HSV DNA in cerebrospinal fluid (CSF) specimens obtained from patients with HSVE (15). In patients with HSVE, this method is now considered the reference standard for laboratory diagnosis with sensitivity and specificity comparable or superior to those of brain biopsy $(16,17)$. PCR has been used to detect HSV DNA in the CSF of patients with "atypical" clinical syndromes. Bell's palsy $(18,19)$, cluster headaches $(20$, 21), migraines (22), and even common recurrent headaches (23) have been suggested to have HSV infection or reactivation as a cause. PCR-based detection may identify those patients who could benefit from antiviral therapy. The newer and more sensitive PCR methods of HSV detection, such as real-time PCR have improved the clinical utility of the test (24). This study assessed the clinical utility of real-time PCR-based detection of HSV DNA in CSF specimens. CSF has been regarded as the best source for rapid and specific diagnosis of HSVE patients. The study aimed to correlate laboratory findings in the CSF with clinical presentations and histories to better define CNS disease due to HSV infection and to improve laboratory diagnosis.

\section{MATERIAL AND METHODS}

Overall, 152 CSF samples were tested from patients with neurological signs referred to Mahdieh Clinical Laboratory in Isfahan from 2010 to 2013. The study was approved by the local ethics committee and written informed consent was obtained from participants before the start of the experiments. Two hundred micro litres of the CSF was used to extract DNA using extraction kit (Ribo perep REf: K2-q-Et-100-CE Amplisinse Biotechnology, Russia) according to the manufacturer's instructions.

Real-time PCR kits (HSV1, 2 Ref: R-V8F9Rg, IQ)-CE, Amplisinse Biotechnology, Russia) were used for detection of HSV DNA. The signal from the HSV1 and HSV2 DNA amplification product was detected in the FAM/Green channel. The program for the PRC process was set according to the manufacturer's manual (Table 1).

Fisher's exact test was used for statistical analysis of obtained data using Graph Pad Instant software version 3.05 (Graph Pad, USA). 
Table 1- program of the real-time PCR thermocycler

\begin{tabular}{cccc}
\hline Step & Temperature $^{\circ} \mathrm{C}$ & Time & Cycles \\
\hline Hold & $\mathbf{9 5}$ & $15 \mathrm{~min}$ & $\mathbf{1}$ \\
Cycle 1 & 95 & $5 \mathrm{sec}$ & 5 \\
& 60 & $20 \mathrm{sec}$ & \\
& 72 & $15 \mathrm{sec}$ & \\
Cycle 2 & 95 & $5 \mathrm{sec}$ & 40 \\
& 60 & $20 \mathrm{sec}^{*}$ & \\
& 72 & $15 \mathrm{sec}$ & \\
\hline
\end{tabular}

\section{RESULTS}

Of the 152 patients tested, 50 were diagnosed with encephalitis. The HSV-positive cases were detected among patients with encephalitis. Three HSV-positive cases were found among patients with no encephalitis (3 out of 102).The minimum viral load (220 copy $/ \mathrm{ml}$ ) and the maximum viral load (32000 copy $/ \mathrm{ml}$ ) were detected in a 2.5 years old male and a 9-month-old female, respectively (table 2). Overall, four of the 152 patients were reported dead with one HSV-positive case that had encephalitis. The frequency of HSV was significantly higher in patients with encephalitis $(\mathrm{p}<0.05)$.

Table2- The frequency of HSV infection in different age groups and cases with and without encephalitis M= Male, F= Female, HSV 1\&2= Herpes simplex virus type 1 and 2

\begin{tabular}{|c|c|c|c|c|c|c|c|c|}
\hline \multirow[b]{2}{*}{ Age } & \multicolumn{4}{|c|}{ Frequency (HSV 1\& 2 +) } & \multicolumn{4}{|c|}{ Frequency (HSV 1\& 2 -) } \\
\hline & $\mathbf{M}$ & $\%$ & $\mathbf{F}$ & $\%$ & $\mathbf{M}$ & $\%$ & $\mathbf{F}$ & $\%$ \\
\hline Less than one month & - & - & - & - & 4 & 2.63 & 1 & 0.65 \\
\hline 1-24 months & 5 & 3.28 & 1 & 0.65 & 53 & 34.86 & 19 & 12.5 \\
\hline 2- 20 years & 1 & 0.65 & - & - & 5 & 3.28 & 2 & 1.31 \\
\hline $20-50$ years & 1 & 0.65 & 1 & 0.65 & 5 & 3.28 & 1 & 0.65 \\
\hline$>50$ years & 3 & 1.97 & 1 & 0.65 & 31 & 20.39 & 18 & 11.84 \\
\hline The range of viral load (copy/ml) & $220-29000$ & - & $6700-32000$ & - & - & - & - & - \\
\hline Encephalitis (-) & 2 & 1.31 & 1 & 0.65 & 68 & 44.73 & 31 & 20.39 \\
\hline
\end{tabular}

\section{DISCUSSION}

One of the most severe viral infections is Encephalitis. So a rapid and accurate detection in initial step of infection is seems beneficial for improving treatment (17). Previous studies showed that there is direct correlation between encephalitis and HSV infection and the diagnosis of HSE by PCR method can reduce the negative results in comparison to imaging finding. Although, DNA viral load of HSV in the early stage of infection can lead to outcome of patients but the most previous papers on HSE showed no association between the initial load of HSV DNA in CSF and the respective outcomes (18).

In this study, CSF samples from 152 patients with neurological signs were tested to determine the correlation between encephalitis and the presence of HSV. Fifty patients were diagnosed with encephalitis, while only 10 of these patients were infected with HSV (20\%). Three HSV-positive cases were found among patients without encephalitis. HSV was significantly $(\mathrm{p}<0.05)$ higher in encephalitis cases indicating the importance of this On the infection as an etiological factor of encephalitis. Consistent with our study findings, other studies in Iran by Ghannad et al. (2013) and Ziyaeyan et al. (2011) reported that HSV was detected in $15 \%$ and $9.3 \%$ of the patients with encephalitis, respectively (17, 18). However, HSV was detected in $92 \%$ and $30 \%$ of patients in studies in Spain and the Middle East, respectively (17). One report from Babol, a northern city in Iran, declared the high rate of patients $(34 \%)$ with encephalitis. Another report from Canada showed that the low rate $(0.3 \%)$ of encephalitis in children with febrile seizures is associated to HSV infection. Also, HSV infection is the most causative factor of encephalitis in Taiwan and $92 \%$ of patients with encephalitis in Spain are HSV positive which may be due to high quality of laboratory diagnosis methods (17). This might be due to different diagnostic tests used. According to our findings and previous studies, the diagnosis of encephalitis based on detection of HSV in CSF of patients is essential. 
other hand, in a study by Ahmadpour and Berari (2010), HSV was detected in $30 \%$ of children with encephalitis (4), while about $60 \%$ of positive encephalitis cases were 1-24 months of age. Recent studies showed that genital herpes is usually transmitted from mother to fetus during delivery (2). Considering the high rate of HSV infection in children with encephalitis, Cesarean section is recommended for HSV-positive mothers to prevent infection in newborns.

It is also shown that the frequency of HSV is higher in individuals aged less than 20 and above 50 years, which is consistent with the results of the present study. Treatment of encephalitis with acyclovir is suggested to investigate the correlation between the HSV

\section{REFERENCES}

1. Sheybani F, Arabikhan H, Naderi H. Herpes Simplex Encephalitis (HSE) and its outcome in the Patients who were Admitted to a Tertiary Care Hospital in Mashhad, Iran, over a 10-year Period. Journal of clinical and diagnostic research. 2013; 7(8): 1626. doi: $10.7860 / J C D R / 2013 / 5661.3221$.

2. Anzivino E, Fioriti D, Mischitelli M, Bellizzi A, Barucca V, Chiarini F, et al. Herpes simplex virus infection in pregnancy and in neonate: status of art of epidemiology, diagnosis, therapy and prevention. Virol J. 2009; 6: 40. doi: 10.1186/1743-422X-6-40.

3. Milatovic D, Zhang Y, Olson SJ, Montine KS, Roberts $\mathrm{LJ}$, Morrow JD, et al. Herpes simplex virus type 1 encephalitis is associated with elevated levels of F2isoprostanes and F4 neuroprostanes. Journal of neurovirology. 2002; 8(4): 295-305.

4. Barari Sawadkohi R, Ahmadpour-kacho M. Clinical Manifestations, Laboratory Findings and Outcomes of Children with Herpetic Encephalitis in Amirkola Children Hospital, Northern Iran. Iranian Red Crescent Medical Journal. 2010; 12(5): 568-71.

5. Ibrahim AI, Obeid MT, Jouma MJ, Roemer K, Mueller-Lantzsch N, Gärtner BC. Prevalence of herpes simplex virus (types 1 and 2), varicella-zoster virus, cytomegalovirus, and human herpesvirus 6 and 7 DNA in cerebrospinal fluid of Middle Eastern patients with encephalitis. Journal of clinical microbiology. 2005; 43(8): 4172-4. doi: 10.1128/JCM.43.8.4172-4174.2005.

6. Boston Interhospital Virus Study Group, NIAIDSponsored Cooperative Antiviral Clinical Study. Failure of high dose 5-iodo-2_-deoxyuridine in the therapy of herpes simplex virus encephalitis: evidence of unacceptable toxicity. The New England Journal of Medicine.1975; 292: 599-603. DOI: 10.1056/NEJM197503202921201.

7. Whitley RJ, Soong SJ, Dolin R, Galasso GJ, Ch'ien LT, Alford CA. Adenine arabinoside therapy of biopsyproved herpes simplex encephalitis: National Institute of viral load and patients' outcomes. In order to avoid unnecessary antiviral treatments, a routine real-time PCR test for HSV diagnosis in patients with encephalitis is suggested.

\section{CONCLUSIONS}

Real-time PCR of CSF specimen is a sensitive, specific and rapid method for HSVE diagnosis, making brain biopsy unnecessary.

\section{ACKNOWLEDGMENTS}

The authors would like to thank staff of the Mahdieh Laboratory for their helpful and constructive comments.

\section{CONFLICT OF INTEREST}

The authors declare no conflict of interest.

Allergy and Infectious Diseases collaborative antiviral study. N Engl J Med. 1977; 297(6): 289-94.

8. Sköldenberg B, Forsgren M, Alestig K, Bergström T, Burman L, Dahlqvist E, et al. Acyclovir versus vidarabine in herpes simplex encephalitis: randomised multicentre study in consecutive Swedish patients. Lancet. 1984; 2(8405): 707-11.

9. Corey L, Whitley RJ, Stone EF, Mohan K. Differences between herpes simplex virus type 1 and type 2 neonatal encephalitis in neurological outcome. Lancet 1988; 1(8575-6): 1-4.

10. Goldsmith SM, Whitley RJ. Herpes simplex encephalitis. In: Lambert HP, ed. Infections of the central nervous system. Philadelphia: BC Decker. 1991: 283-99.

11. Fodor PA, Levin MJ, Weinberg A, Sandberg E, Sylman J, Tyler KL. Atypical herpes simplex virus encephalitis diagnosed by PCR amplification of viral DNA from CSF. Neurology. 1998; 51(2): 554-9.

12. Nahmias AJ, Whitley RJ, Visintine AN, Takei Y, Alford CA Jr. Herpes simplex virus encephalitis: laboratory evaluations and their diagnostic significance. Journal of Infectious Diseases. 1982; 145(6): 829-36.

13. Read SJ, Kurtz JB. Laboratory diagnosis of common viral infections of the central nervous system by using a single multiplex PCR screeningassay. Journal of Clinical Microbiology. 1999; 37(5): 1352-5.

14. Simko P, Caliendo MA, Hogle K, Versalovic J. Differences in Laboratory Findings for Cerebrospinal Fluid Specimens Obtained from Patients with Meningitis or Encephalitis Due to Herpes Simplex Virus (HSV) Documented by Detection of HSV DNA. Clinical Infectious Diseases. 2002; 35(4): 414-419.

15. Rowley AH, Whitley RJ, Lakeman FD, Wolinsky SM. Rapid detection of herpes simplex virus DNA in CSF of patients with herpes simplex encephalitis. Lancet .1990; 335(8687): 440-4. PMID:1968171. 
16. Lakeman FD, Whitley RJ. Diagnosis of herpes simplex encephalitis: application of polymerase chain reaction to cerebrospinal fluid from brain-biopsied patients and correlation with disease. National Institute of Allergy and Infectious Diseases Collaborative Antiviral Study Group. Journal of Infectious Diseases.1995; 171(4): 857-63.

17. Ghannad MS, Solgi G, Hashemi SH, ZebarjadyBagherpour J, Hemmatzadehm A, Hajilooi M. Herpes
Simplex Virus Encephalitis in Hamadan, Iran. Iranian journal of microbiology. 2013; 5(3): 272-77. PMCID: PMC3895567.

18. Ziyaeyan M, Alborzi A, Haghighi AB, Jamalidoust M, Moeini M, Pourabbas B. Diagnosis and quantitative detection of HSV DNA in samples from patients with suspected herpes simplex encephalitis. Brazilian Journal of Infectious Diseases. 2011; 15(3): 211-4. 